\title{
One size does not fit all
}

\section{The recent proposal from the European Commission (EC) for a new directive on the protection of animals used in research is well intentioned, but some of its ramifications could cause it to backfire.}

$\mathbf{T}$ he use of animals in research has long been a matter of concern to the general public, particularly in Europe. As the current, two-decades-old European directive on animal protection is widely regarded as outdated, the recent EC proposal to establish a new set of minimal standards of animal care that takes into account public opinion, scientific considerations and the economic competitiveness of Europe is a welcome development (see page 1293).

When drafting the new directive, the authors of the proposal took a very thoughtful and disciplined approach. For every change suggested, the EC tried to quantify as objectively as possible the cost and benefit of its implementation in economic, animal welfare, scientific and societal terms. For example, when proposing the creation of ethics committees to ensure that researchers throughout Europe observe the minimal standards of care, the directive estimated that $\sim 12$ million animals would benefit every year at an administrative cost of $\sim € 9$ million. This change, according to the proposal, would also increase public perception of accountability and keep Europe from spending up to $€ 70$ million in projects that do not meet the proposed standards.

Although one may wonder about the accuracy of some of these estimates, the directive has other, more profound potential problems that could end up hurting, instead of promoting, scientific competitiveness at both the national and European levels.

Throughout the draft, the EC states that a key goal of the directive is to "ensure a fair and level playing field" for industry and researchers across Europe. As the current European directive is outdated, some countries have unilaterally decided to enact their own tougher animal welfare regulations. But in the EC's view, countries with high animal care standards have higher costs and regulatory burdens that place them at a competitive disadvantage against nations with more relaxed regulations.

To address this disparity, the EC looked at the regulations of each of its member states and, broadly speaking, set the new standards at the level of the highest benchmarks currently found anywhere in Europe. In an example that has many critics cringing, animal welfare regulations in Germany include "sentient invertebrates." So the EC directive now includes cephalopods and some crustaceans as species that require protection throughout the continent.

Leveling the playing field is a good idea, but it's hard to see how countries that already have high standards of animal care-the UK, Germany, Sweden - are the ones at a disadvantage versus, say, the newest members of the EU. In fact, it's easier to imagine that the science budget of countries such as Croatia, which are making a serious but incipient effort to foster research, may take a substantial hit by having to pay for additional bureaucracy to enact the new rules. So the existing gap between more and less scientifically developed European nations could actually widen as a result of the directive.

The EC also studied animal welfare standards throughout the world and determined that its directive is in line with regulations already in place in other countries-even though, for example, the US Animal Welfare Act does not protect rats, mice and birds. And although the EC also acknowledged that low protection standards probably exist in places such as China, it concluded that organizations outsource projects to that country because of wage differentials and not in connection with the permissiveness of its animal welfare laws. However, the possibility that the latest directive will become a new incentive for animal researchers to turn their eyes to East Asia cannot be discounted.

Animal welfare certainly must not take a backseat to economic considerations, and the creation of a new directive of animal care is to be commended. However, the EC should ponder whether ratcheting up its regulations to meet the tough standards of nations that have introduced some of their policies in response to animal activism strikes an adequate balance between animal rights and the needs of countries with a fledgling scientific base.

From a broader perspective, the EC's effort to ensure the same opportunities for all its citizens-its push for a level playing field—is also commendable. But Europe shouldn't forget that, just as the states of California and Montana have very different economies but both contribute to US growth, there has to be equilibrium between pushing for homogenization and playing to the strengths of the continent's richly diverse member states. 